\section{RICYDE. Revista Internacional de Ciencias del Deporte doi: $10.5232 /$ ricyde \\ Rev. Int. cienc. deporte}

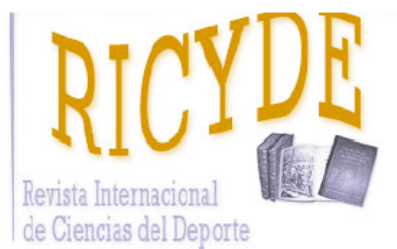

RICYDE. Revista Internacional de Ciencias del Deporte Volume XVI - Year XVI

Pages: $12-23$ - ISSN: $1885-3137$

Issue 59 - January 2020

\title{
How best to quantify home advantage in team sports: an investigation involving male senior handball leagues in Portugal and Spain \\ La mejor manera de cuantificar la ventaja de jugar en casa en deportes de equipo: una investigación con ligas de Balonmano senior masculino en Portugal y España
}

\author{
Rui Matos ${ }^{1,2}$, Nuno Amaro ${ }^{1,2,3}$, Richard Pollard ${ }^{4}$
}

1. Instituto Politécnico de Leiria. Portugal

2. Life Quality Research Center (CIEQV). Portugal

3. Research Center in Sports Sciences, Health Sciences and Human Development (CIDESD). Portugal

4. California Polytechnic State University. United States

\begin{abstract}
Home advantage $(\mathrm{HA})$, or the effect of match location, has been shown to play an important role in determining the result of a game. A method introduced over 30 years ago has enjoyed wide use. However, there is a possible problem with its interpretation. Although this can be overcome by rescaling the original value for $\mathrm{HA}$, this paper introduces a somewhat different approach to quantifying $\mathrm{HA}$, one that is derived by expressing home performance specifically as a function of away performance. The various methods are illustrated by analyzing HA for teams in the men's professional handball leagues in Portugal and Spain for the 2016-17 season. Results show that the traditional and rescaled methods both ensure a maximum value of $100 \%$ for $\mathrm{HA}$, while the new method can produce values well above $100 \%$. Also, when HA is small, as in the case of goals scored and conceded, then values from the new method are about twice those from the rescaled method. However, when HA is larger, as in the case of most of the teams in the lower half of the Spanish league table, when based on points, the new method produces HA values which are much higher that the rescaled. This method provides a new dimension to consider when trying to quantify HA. It has the advantage of also being appropriate for the difference between goals scored and goals conceded. Choice of methodology will depend on the specific objective being sought when studying the effect of HA on performance.
\end{abstract}

Key words: home advantage, quantification, goal differential, handball, team sports.

\section{Resumen}

Se ha demostrado que la ventaja en jugar en casa (HA), o el efecto de la ubicación del partido, juega un papel importante en la determinación del resultado de un juego. Un método introducido hace más de 30 años ha gozado de amplio uso. Sin embargo, hay un posible problema con su interpretación. Aunque esto se puede solucionar por reescalar el valor original para $\mathrm{HA}$, este trabajo presenta un enfoque algo diferente a la cuantificación de HA, uno que es derivado de la expresión del rendimiento en casa específicamente como una función del rendimiento fuera de casa. Los distintos métodos se ilustran mediante el análisis de HA de los equipos de las principales ligas de balonmano profesional masculino en Portugal y España para la temporada 2016-17. Los resultados muestran que tanto los métodos tradicionales como los reescalados aseguran un valor máximo de $100 \%$ de $\mathrm{HA}$, mientras que el nuevo método puede producir valores muy por encima de $100 \%$. También, cuando HA es pequeño, como en el caso de los goles marcados y concedidos, entonces los valores de este nuevo método son sobre dos veces los del método reescalado. Sin embargo, cuando HA es más grande, como en el caso de la mayoría de los equipos en la mitad inferior de la tabla de la Liga española, cuando se basa en puntos, el nuevo método produce HA valores mucho más altos que lo reescalado. Este método proporciona una nueva dimensión a tener en cuenta cuando se intenta cuantificar HA. Tiene la ventaja de también ser apropiado para la diferencia entre goles marcados y goles concedidos. La elección de la metodología dependerá del objetivo específico que se busque al estudiar el efecto de la ventaja de jugar en casa en el rendimiento deportivo. Palabras clave: ventaja de jugar en casa; cuantificación; diferencial de goles; balonmano; deportes de equipo. 
Matos, R.; Amaro, N., \& Pollard, R. (2020). How best to quantify home advantage in team sports: an investigation involving male senior handball leagues in Portugal and Spain. RICYDE. Revista internacional de ciencias del deporte, 59(16), 12-23.

https://doi.org/10.5232/ricyde2020.05902

\section{Introduction}

$\mathrm{H}$ ome advantage (HA) is a well-known and well-documented phenomenon that occurs in most professional team sports (Nevill \& Holder, 1999; Gómez, Pollard, \& Luis-Pascual, 2011; Pollard, Prieto and Gómez, 2017; Jones, 2018). Many explanations have been put forward to account for this advantage, but relatively little work has been carried out as to how the magnitude of this advantage should best be quantified and interpreted in a way that it can be compared between sports, between leagues and between teams within a league.

Early studies on HA simply compared the home record of teams with the away record, without attempting to quantify the magnitude of the advantage (e.g. Edwards, 1979; Schwartz \& Barsky, 1977). In a study of HA in football, mostly in England, Pollard (1986) introduced a measure to quantify HA by expressing the number of points won at home as a percentage of all points won at home and away. This methodology could be applied both to complete leagues as well as to individual teams within a league, allowing comparisons of the magnitudes to be made. For example, for a football league in a season, if 450 points were won by teams playing at home and 250 by the away teams, HA could be quantified as $450 / 700=64.3 \%$. It was emphasized that for this to be a valid measure, the teams should have played a balanced schedule of games, each playing each other twice, once at home and once away. Subsequent studies comparing different sports and leagues (e.g. Courneya \& Carron, 1992; Gómez, LagoPeñas, \& Pollard, 2013; Jamieson, 2010; Nevill \& Holder, 1999; Smith, 2003.), mostly in the U.S., used 'home winning percentage', or HWP, to quantify HA, essentially the same as Pollard's method, when applied to sports that do not allow tied results and always finish with one team winning and the other losing. An ambitious international study by Pollard, Prieto and Gómez (2017) compared HA in 15 different sports in 65 countries. Because different sports and different countries used different methods of allocating points based on the result of a game (win, draw (tie), loss), the measure of HA was standardized by awarding 2 points for a win, one point for a draw and zero points for a loss, whatever the actual system in place. This enabled meaningful comparisons of HA to be made between countries and between sports, the method used to quantify HA being the same as that used by Pollard (1986) and essentially the same as home winning percentage, as used by other authors, if a tie is counted as half a win.

Although Pollard's method produces a numerical value to represent HA and has been in wide use, there is a potential problem with its interpretation. For example, if teams in a league win the same number of points at home and away, HA will be quantified as $50 \%$ while in fact there is no home advantage. In the previous example above, the interpretation of the value of $64.3 \%$ HA is open to some uncertainty, although its meaning is unambiguous: $64.3 \%$ of total points in the league were won by the team playing at home. Furthermore, a value of $40 \%$ home advantage would actually represent a home disadvantage. These difficulties in interpretation can easily be overcome by re-scaling the HA values. The original value of HA varies between $50 \%$ and $100 \%$, while values between $0 \%$ and $50 \%$ would actually represent a home disadvantage. An easier way to interpret range of values for HA would be $0 \%$ (no HA) to $100 \%$, with negative values representing a home disadvantage. The value of $64.3 \%$ HA would then become, on the new scale, $(64.3-50) / 50=0.286$, or $28.6 \%$. In other words, on a HA scale of $0 \%$ to $100 \%$, this team obtained a HA of $28.6 \%$. 
Matos, R.; Amaro, N., \& Pollard, R. (2020). How best to quantify home advantage in team sports: an investigation involving male senior handball leagues in Portugal and Spain. RICYDE. Revista internacional de ciencias del deporte, 59(16), 12-23.

https://doi.org/10.5232/ricyde2020.05902

Using a mathematical modeling approach, Stefani (2007) arrived at a formula for calculating HA for leagues that produced similar, and in some cases, identical values to Pollard's method. This will be described in more detail in the next section. Somewhat different methodology has been developed to compare the home advantage of specific teams within a league (e.g. Clarke \& Norman, 1995; Goumas, 2017). Other approaches to quantifying HA are possible and the measure of performance need not necessarily be the game result, with goals, shots or other performance variables being perfectly valid choices. Some clearly inappropriate methods of quantifying HA have also been used, usually confusing home performance with home advantage (e.g. Saavedra, Gutiérrez, Sa Marquez, Torres, \& Fernández, 2013), as discussed by Gómez and Pollard (2014).

The purpose of this paper is to explore a number of alternative methods of quantifying HA and to assess their values and interpretations against the traditional methodology. This will focus on methods that can be used in the same way to quantify HA for both complete leagues as well as for each team within a league.

\section{Methods}

\section{Choice of data set}

In order to illustrate the various methods of quantifying HA, an appropriate data set was needed. Professional handball was chosen as an appropriate data set sport, using the most recent season for which a final league table was available (2016-2017) and for two neighbouring countries, Portugal and Spain, these being countries with differing skill levels, recent world ranking having Spain at number 8 and Portugal at 35. A further advantage of using handball data was that the sport has recently been shown to have the highest HA worldwide of any sport other than basketball (Pollard et al., 2017). A number of previous studies of HA in professional handball have also demonstrated the importance that HA plays in determining the outcome of games in elite national leagues in European countries. Most of these reports relate specifically to handball in Spain (Gómez, Pollard, \& Luis-Pascual, 2011; Lago-Peñas, Gómez, Viaño, González-García, \& Fernández-Villarino, 2013; Oliveira, Gómez, \& Sampaio, 2012; Pollard \& Gómez, 2012), but the same HA effect has been demonstrated to exist in other elite national handball leagues in Europe (Meletakos \& Baylos, 2010). Other investigations into the effect of HA in handball have looked at how game location influences patterns of play (Pic, 2018), goal difference (Debanne \& Laffaye, 2017) and game related statistics (Gómez, Lago-Peñas, Viaño, \& González-Garcia, 2014).

Final league tables for the Spanish and Portuguese national handball leagues for the season 2016-2017 were accessed from the website www.meusresultados.com. Only the regular season was used, not the play-offs, since the regular season was played with a balanced schedule of games, each team playing each other twice, once at home and once away, a requirement for an unbiased measure of home advantage.

\section{Different methods of quantifying home advantage}

The Portuguese and Spanish handball main male championships allocate different points to wins, draws and defeats (respectively 3,2 and 1 in Portugal and 2, 1 and 0 in Spain). In order to standardize the analysis, as well as any comparison between countries, the same method of points allocation for each country was employed, choosing the more conventional Spanish method of awarding two points for a win, one for a draw and zero for a loss/defeat. The following methods of quantifying HA were used, where: 
$\mathrm{H}=$ number of points won at home

$\mathrm{A}=$ number of points won away

$\mathrm{W}=$ number of home wins

$\mathrm{D}=$ number of home draws

$\mathrm{L}=$ number of home losses

$\mathrm{N}=$ total number of games

The following formulas can be used to calculate the HA of a whole league,

\section{Pollard's traditional method}

$\mathrm{HA}(\operatorname{trad})=(\mathrm{H} /(\mathrm{H}+\mathrm{A}))^{*} 100 \%$. In other words, the number of points won at home expressed as a percentage of all point won at home and away. This measure is always non-negative and varies from $0 \%$ (no points won at home) to $100 \%$ (no points won away), with a value of $50 \%$ representing an equal number of points won at home and away (i.e. no home advantage). It gives an easy to calculate measure of HA, but can be criticized on the grounds that the value obtained does not properly relate to the advantage of playing at home, and that the reference point of no home advantage should be $0 \%$ rather than $50 \%$. To overcome this problem interpretation, a rescaled value can be obtained as follows:

\section{Pollard's rescaled method}

HA $($ rescaled $)=(($ HA $(\operatorname{trad})-50) / 50) * 100 \%$. This method will produce a value of $0 \%$ when the same number of points are won at home and away (no home advantage), with the advantage then being measured on a scale between $0 \%$ to $100 \%$, while negative values will indicate a home disadvantage. In terms of points won and lost, the formula for this method can be expressed as: $\mathrm{HA}($ rescaled $)=((\mathrm{H}-\mathrm{A}) /(\mathrm{H}+\mathrm{A})) * 100 \%$. Jones $(2018)$ used a similar concept to this method, with a slightly different scaling procedure, but this need not be considered as a separate method due its close mathematical relationship. The formula used reduces to $0.5 *(\mathrm{H}-$ A) $/(\mathrm{H}+\mathrm{A})$, which has a basic equivalence to the rescaled method.

\section{Stefani's method}

$\mathrm{HA}($ Stefani $)=((\mathrm{W}-\mathrm{L}) / \mathrm{N}) * 100 \%$. This method is derived from a mathematical model for $\mathrm{HA}$ and results in a formula which ignores draws and leads to a value which will vary from $0 \%$ (no home advantage) to $100 \%$, thus avoiding the problem in interpretation in Pollard's traditional method. Negative values will indicate a home disadvantage. It should be noted that this method excludes draws in the denominator, but includes them in the numerator.

\section{New method}

Consideration was then given to a somewhat different approach.

$\mathrm{HA}($ new $)=((\mathrm{H}-\mathrm{A}) / \mathrm{A}) * 100 \%$. This method gives the difference between home and away points expressed as a percentage of the number of away points. The measure is undefined if no points are won away. It can be negative when more points are won away than at home (a home disadvantage) with a lower limit of $-100 \%$ which will occur when no points are won at home. It will be positive when a home advantage exists, with an upper limit of $(\mathrm{H}-1)^{*} 100 \%$ which is well above $100 \%$. As with both Pollard's rescaled method and Stefani's method, no home advantage is represented by a value of zero, a positive value indicates the existence of a home advantage and a negative value, a home disadvantage. 
Matos, R.; Amaro, N., \& Pollard, R. (2020). How best to quantify home advantage in team sports: an investigation involving male senior handball leagues in Portugal and Spain. RICYDE. Revista internacional de ciencias del deporte, 59(16), 12-23.

https://doi.org/10.5232/ricyde2020.05902

It should be noted that Pollard's two methods and the new method can be used to calculate HA, not just based on points won, but also on goals scored or goals conceded. They can also be used to calculate HA for each individual team within a league. Furthermore, the new method also lends itself for use with goal differential (goals scored - goals conceded). However, in this case, negative values may occur (when a team concedes more goals than it scores, either at home, away from home, or both), unlike when HA is based on points or goals (which are never negative). Thus, the new method can be used in this situation, but to avoid misleading interpretations a slight modification to the formula needs to be made. The absolute value of away performance in the denominator needs to be used: HA (goal differential) $=((\mathrm{H}-\mathrm{A}) /|\mathrm{A}|)^{*}$ $100 \%$. Without this modification, a HA might become an apparent HD and vice-versa, leading to erroneous conclusions and interpretations.

In contrast, Stefani's method is only appropriate for use with the game outcomes (win, draw, loss). It cannot be used for individual teams within a league, neither can it be applied to goals scored or conceded.

\section{Relationship between different methods}

There are simple mathematical relationships between the three methods that can be used both for points and goals. These are as follows:

To transform HA (trad) to HA (rescaled), multiply by (H-A)/H

To transform HA (trad) to HA (new), multiply by $(\mathrm{H}-\mathrm{A}) *(\mathrm{H}+\mathrm{A}) /\left(\mathrm{H}^{*} \mathrm{~A}\right)$

To transform HA (rescaled) to HA (new), multiply by $(\mathrm{H}+\mathrm{A}) / \mathrm{A}$

\section{Results}

Tables 1 and 2 give the final league tables for each league. These tables provide the raw data on which the investigation was based. They give the home and away record for each team, both in terms of the result of the relevant matches (win - W, draw - D or lose - L), as well as goals scored (GS), goals conceded (GC) and goal differential (GD).

Table 1. Final league table for Portugal (Andebol 1), 2016-2017

\begin{tabular}{|c|c|c|c|c|c|c|c|c|c|c|c|c|c|c|c|}
\hline \multirow[b]{2}{*}{ Team } & \multicolumn{7}{|c|}{ HOME } & \multicolumn{7}{|c|}{ AWAY } & \multirow{2}{*}{$\begin{array}{l}\text { Total } \\
\text { points }\end{array}$} \\
\hline & $\mathrm{W}$ & $\mathrm{D}$ & $\mathrm{L}$ & Pts & GS & $\mathrm{GC}$ & GD & $\mathrm{W}$ & $\mathrm{D}$ & $\mathrm{L}$ & Pts & GS & $\mathrm{GC}$ & GD & \\
\hline Porto & 13 & 0 & 0 & 26 & 426 & 313 & 113 & 13 & 0 & 0 & 26 & 400 & 304 & 96 & 52 \\
\hline Sporting & 11 & 0 & 2 & 22 & 423 & 319 & 104 & 12 & 0 & 1 & 24 & 440 & 329 & 111 & 46 \\
\hline ABC Braga & 10 & 1 & 2 & 21 & 429 & 344 & 85 & 9 & 0 & 4 & 18 & 409 & 358 & 51 & 39 \\
\hline Benfica & 10 & 0 & 3 & 20 & 392 & 314 & 78 & 9 & 0 & 4 & 18 & 382 & 331 & 51 & 38 \\
\hline Madeira & 8 & 0 & 5 & 16 & 406 & 370 & 36 & 7 & 1 & 5 & 15 & 388 & 335 & 53 & 31 \\
\hline Águas Santas & 7 & 2 & 4 & 16 & 326 & 316 & 10 & 6 & 1 & 6 & 13 & 335 & 347 & -12 & 29 \\
\hline Avanca & 8 & 1 & 4 & 17 & 334 & 321 & 13 & 4 & 2 & 7 & 10 & 333 & 363 & -30 & 27 \\
\hline Maia-Ismai & 7 & 1 & 5 & 15 & 374 & 368 & 6 & 2 & 3 & 8 & 7 & 330 & 384 & -54 & 22 \\
\hline AC Fafe & 5 & 1 & 7 & 11 & 319 & 363 & -44 & 3 & 1 & 9 & 7 & 331 & 378 & -47 & 18 \\
\hline Boa Hora & 3 & 2 & 8 & 8 & 314 & 394 & -80 & 4 & 1 & 8 & 9 & 349 & 397 & -48 & 17 \\
\hline Belenenses & 3 & 2 & 8 & 8 & 364 & 388 & -24 & 4 & 0 & 9 & 8 & 346 & 385 & -39 & 16 \\
\hline Arsenal & 3 & 1 & 9 & 7 & 365 & 404 & -39 & 1 & 4 & 8 & 6 & 342 & 413 & -71 & 13 \\
\hline SC Horta & 2 & 2 & 9 & 8 & 325 & 392 & -67 & 1 & 3 & 9 & 5 & 337 & 388 & -51 & 11 \\
\hline São Mamede & 1 & 3 & 9 & 6 & 302 & 379 & -77 & 0 & 0 & 13 & 0 & 263 & 387 & -124 & 5 \\
\hline
\end{tabular}


Matos, R.; Amaro, N., \& Pollard, R. (2020). How best to quantify home advantage in team sports: an investigation involving male senior handball leagues in Portugal and Spain. RICYDE. Revista internacional de ciencias del deporte, 59(16), 12-23.

https://doi.org/10.5232/ricyde2020.05902

Table 2. Final league table for Spain (ASOBAL), 2016-2017

\begin{tabular}{|c|c|c|c|c|c|c|c|c|c|c|c|c|c|c|c|}
\hline \multirow[b]{2}{*}{ Team } & \multicolumn{7}{|c|}{ HOME } & \multicolumn{7}{|c|}{ AWAY } & \multirow{2}{*}{$\begin{array}{l}\text { Total } \\
\text { points }\end{array}$} \\
\hline & $\mathrm{W}$ & $\mathrm{D}$ & $\mathrm{L}$ & Pts & GS & $\mathrm{GC}$ & GD & $\mathrm{W}$ & $\mathrm{D}$ & $\mathrm{L}$ & Pts & GS & $\mathrm{GC}$ & GD & \\
\hline Barcelona & 15 & 0 & 0 & 30 & 518 & 376 & 142 & 15 & 0 & 0 & 30 & 480 & 364 & 116 & 60 \\
\hline Ademar & 14 & 0 & 1 & 28 & 444 & 368 & 76 & 11 & 1 & 3 & 23 & 422 & 380 & 42 & 51 \\
\hline La Rioja & 12 & 0 & 3 & 24 & 459 & 368 & 91 & 8 & 2 & 5 & 18 & 430 & 414 & 16 & 42 \\
\hline Granollers & 11 & 1 & 3 & 23 & 439 & 393 & 46 & 6 & 2 & 7 & 14 & 414 & 423 & -9 & 37 \\
\hline Anaitasuna & 9 & 1 & 5 & 19 & 425 & 396 & 29 & 5 & 3 & 7 & 13 & 399 & 414 & -15 & 32 \\
\hline Cuenca & 7 & 4 & 4 & 18 & 419 & 404 & 15 & 6 & 1 & 8 & 13 & 388 & 422 & -34 & 31 \\
\hline Huesca & 9 & 1 & 5 & 19 & 394 & 386 & 8 & 5 & 1 & 9 & 11 & 366 & 410 & -44 & 30 \\
\hline Atl. Valladolid & 12 & 0 & 3 & 24 & 448 & 393 & 55 & 2 & 0 & 13 & 4 & 392 & 439 & -47 & 28 \\
\hline Puente Genil & 8 & 3 & 4 & 19 & 413 & 410 & 3 & 2 & 2 & 11 & 6 & 399 & 440 & -41 & 25 \\
\hline Guadalajara & 8 & 0 & 7 & 16 & 414 & 420 & -6 & 4 & 0 & 11 & 8 & 381 & 442 & -61 & 24 \\
\hline CD Bidasoa Irun & 7 & 2 & 6 & 16 & 404 & 409 & -5 & 3 & 1 & 11 & 7 & 391 & 428 & -37 & 23 \\
\hline Puerto Sagunto & 7 & 2 & 6 & 16 & 379 & 385 & -6 & 2 & 3 & 10 & 7 & 385 & 420 & -35 & 23 \\
\hline Benidorm & 8 & 2 & 5 & 18 & 394 & 390 & 4 & 1 & 1 & 13 & 3 & 361 & 417 & -56 & 21 \\
\hline Morrazo Cangas & 7 & 2 & 6 & 16 & 421 & 440 & -19 & 2 & 0 & 13 & 4 & 377 & 458 & -81 & 20 \\
\hline Villa de Aranda & 5 & 1 & 9 & 11 & 397 & 430 & -33 & 3 & 3 & 9 & 9 & 406 & 429 & -23 & 20 \\
\hline BM Sinfin & 4 & 1 & 10 & 9 & 382 & 408 & -26 & 2 & 0 & 13 & 4 & 385 & 450 & -65 & 13 \\
\hline
\end{tabular}

Table 3 summarizes the results for the two leagues by combining the records of all teams in each league. It also shows the values, based on points, for the home advantage of each whole league and for each of the four methods under consideration. Table 4 does the same analysis for each league, but based on goals scored and conceded rather than points.

Based on game outcome, HA is clearly higher in Spain than in Portugal, as indicated by all four methods, although the magnitude of the difference shows some variation (Table 3). When based on goals, HA values are much smaller (Table 4), the difference between goals and points being especially evident for Spain.

Table 3. Home advantage based on game results for each country in 2016-2017 season.

\begin{tabular}{|c|c|c|c|c|c|c|c|c|c|c|c|}
\hline \multirow[b]{2}{*}{ Country } & \multicolumn{4}{|c|}{ Home record } & \multirow{2}{*}{$\begin{array}{l}\text { Home } \\
\text { points }\end{array}$} & \multirow{2}{*}{$\begin{array}{l}\text { Away } \\
\text { points }\end{array}$} & \multirow{2}{*}{$\begin{array}{l}\text { Total } \\
\text { points }\end{array}$} & \multicolumn{4}{|c|}{ Home advantage } \\
\hline & Played & Won & Drawn & Lost & & & & Traditional & Rescaled & Stefani & New \\
\hline Portugal & 182 & 91 & 16 & 75 & 198 & 166 & 364 & $54.40 \%$ & $8.79 \%$ & $8.79 \%$ & $19.28 \%$ \\
\hline Spain & 240 & 143 & 20 & 77 & 306 & 174 & 480 & $63.75 \%$ & $27.50 \%$ & $35.83 \%$ & $75.86 \%$ \\
\hline
\end{tabular}

Table 4. Home advantage based on goals scored for each country in 2016-2017 season.

\begin{tabular}{lllllll}
\hline \multirow{2}{*}{ Country } & \multicolumn{2}{l}{ Goals scored } & \multicolumn{3}{l}{ Home advantage } \\
\cline { 2 - 7 } & Home & Away & Total & Traditional & Rescaled & New \\
\hline Portugal & 5099 & 4985 & 10084 & $50.57 \%$ & $1.13 \%$ & $2.29 \%$ \\
\hline Spain & 6750 & 6376 & 13126 & $51.42 \%$ & $2.85 \%$ & $5.87 \%$ \\
\hline
\end{tabular}


Matos, R.; Amaro, N., \& Pollard, R. (2020). How best to quantify home advantage in team sports: an investigation involving male senior handball leagues in Portugal and Spain. RICYDE. Revista internacional de ciencias del deporte, 59(16), 12-23.

https://doi.org/10.5232/ricyde2020.05902

Table 5 shows home advantage for each individual team in the Portuguese league, based on points, goals scored, goals conceded and goal differential. This is done separately for the various methods under consideration. Table 6 does the same thing for teams in the Spanish league. Tables 5 and 6 show considerable variation between teams, both in Portugal and Spain when considering HA based on points, but much less so when based on goals, either scored or conceded.

Table 5. Home advantage for individual teams in Portugal, based on different performance measures and on different method of quantifying HA.

\begin{tabular}{|c|c|c|c|c|c|c|c|c|c|c|}
\hline \multirow{3}{*}{ Team } & \multicolumn{10}{|c|}{ Home advantage (\%) based on: } \\
\hline & \multicolumn{3}{|c|}{ Points } & \multicolumn{3}{|c|}{ Goals scored } & \multicolumn{2}{|c|}{ Goals conceded } & \multicolumn{2}{|r|}{ Goal diff } \\
\hline & $\mathrm{T}$ & $\mathrm{R}$ & $\mathrm{N}$ & $\mathrm{T}$ & $\mathrm{R}$ & $\mathrm{N}$ & $\mathrm{T}$ & $\mathrm{R}$ & $\mathrm{N}$ & $\mathrm{N}$ \\
\hline Porto & 50.00 & 0.00 & 0.00 & 51.57 & 3.14 & 6.50 & 49.27 & -1.46 & -2.88 & 17.8 \\
\hline Sporting & 47.83 & -4.34 & -8.33 & 49.02 & -1.96 & -3.86 & 50.77 & 1.54 & 3.13 & -6.3 \\
\hline ABC Braga & 53.85 & 7.70 & 16.67 & 51.19 & 2.38 & 4.89 & 51.00 & 2.00 & 4.07 & 66.8 \\
\hline Benfica & 52.63 & 5.26 & 11.11 & 50.65 & 1.30 & 2.62 & 51.32 & 2.64 & 5.41 & 53.1 \\
\hline Madeira & 51.61 & 3.22 & 6.67 & 51.13 & 2.26 & 4.64 & 47.52 & -4.96 & -9.46 & -32.1 \\
\hline Águas Santas & 55.17 & 10.34 & 23.08 & 49.32 & -1.36 & -2.69 & 52.34 & 4.68 & 9.81 & 183.7 \\
\hline Avanca & 62.96 & 25.92 & 70.00 & 50.07 & 0.14 & 0.30 & 53.07 & 6.14 & 13.08 & 143.3 \\
\hline Maia-Ismai & 68.18 & 36.36 & 114.29 & 53.13 & 6.26 & 13.33 & 51.06 & 2.12 & 4.35 & 111.1 \\
\hline AC Fafe & 61.11 & 22.22 & 57.14 & 49.08 & -1.84 & -3.63 & 51.01 & 2.02 & 4.13 & 6.6 \\
\hline Boa Hora & 47.06 & -5.88 & -11.11 & 47.36 & -5.28 & -10.03 & 50.19 & 0.38 & 0.76 & -66.7 \\
\hline Belenenses & 50.00 & 0.00 & 0.00 & 51.27 & 2.54 & 5.20 & 49.81 & -0.38 & -0.77 & 38.3 \\
\hline Arsenal & 53.85 & 7.70 & 16.67 & 51.63 & 3.26 & 6.73 & 50.55 & 1.10 & 2.23 & 45.1 \\
\hline SC Horta & 61.54 & 23.08 & 60.00 & 49.09 & -1.82 & -3.56 & 49.74 & -0.52 & -1.02 & -31.4 \\
\hline São Mamede & 100.00 & 100.00 & $*$ & 53.45 & 6.90 & 14.83 & 50.52 & 1.04 & 2.11 & 37.9 \\
\hline
\end{tabular}

Note: * indicates undefined. $\mathrm{T}=$ traditional. $\mathrm{R}=$ rescaled. $\mathrm{N}=$ new.

Table 6. Home advantage for individual teams in Spain, based on different performance measures and on different method of quantifying HA.

\begin{tabular}{lcccccccccc}
\hline \multirow{2}{*}{ Team } & \multicolumn{1}{l}{ Home advantage (\%) based on: } \\
\cline { 2 - 13 } & \multicolumn{1}{l}{ Points } & \multicolumn{3}{c}{ Goals scored } & \multicolumn{3}{c}{ Goals conceded } & Goal diff. \\
\cline { 2 - 13 } & $\mathrm{T}$ & $\mathrm{R}$ & $\mathrm{N}$ & $\mathrm{T}$ & $\mathrm{R}$ & $\mathrm{N}$ & $\mathrm{T}$ & $\mathrm{R}$ & $\mathrm{N}$ & $\mathrm{N}$ \\
\hline Barcelona & 50.00 & 0.00 & 0.00 & 51.90 & 3.80 & 7.92 & 49.19 & -1.62 & -3.19 & 22.5 \\
\hline Ademar & 54.90 & 9.80 & 21.74 & 51.27 & 2.54 & 5.21 & 50.80 & 1.60 & 3.26 & 81.1 \\
\hline La Rioja & 57.14 & 14.28 & 33.33 & 51.63 & 3.26 & 6.74 & 52.94 & 5.88 & 12.50 & 467.3 \\
\hline Granollers & 62.16 & 24.32 & 64.29 & 51.47 & 2.94 & 6.04 & 51.84 & 3.68 & 7.63 & 611.7 \\
\hline Anaitasuna & 59.38 & 18.76 & 46.15 & 51.58 & 3.16 & 6.52 & 51.11 & 2.22 & 4.55 & 293.3 \\
\hline Cuenca & 58.06 & 16.12 & 38.46 & 51.92 & 3.84 & 7.99 & 51.09 & 2.18 & 4.46 & 144.1 \\
\hline Huesca & 63.33 & 26.66 & 72.73 & 51.84 & 3.68 & 7.65 & 51.51 & 3.02 & 6.22 & 118.1 \\
\hline Atl. Valladolid & 85.71 & 71.42 & 500.00 & 53.33 & 6.66 & 14.29 & 52.76 & 5.52 & 11.70 & 217.3 \\
\hline Puente Genil & 76.00 & 52.00 & 216.67 & 50.86 & 1.72 & 3.51 & 51.76 & 3.52 & 7.32 & 107.3 \\
\hline Guadalajara & 66.67 & 33.34 & 100.00 & 52.08 & 4.16 & 8.66 & 51.28 & 2.56 & 5.24 & 90.2 \\
\hline CD Bidasoa Irun & 69.57 & 39.14 & 128.57 & 50.82 & 1.64 & 3.32 & 51.14 & 2.28 & 4.65 & 86.6 \\
\hline Puerto Sagunto & 69.57 & 39.14 & 128.57 & 49.61 & -0.78 & -1.56 & 52.17 & 4.34 & 9.09 & 82.8 \\
\hline Benidorm & 85.71 & 71.42 & 500.00 & 52.19 & 4.38 & 9.14 & 51.67 & 3.34 & 6.92 & 107.2 \\
\hline Morrazo Cangas & 80.00 & 60.00 & 300.00 & 52.76 & 5.52 & 11.67 & 51.00 & 2.00 & 4.09 & 76.5 \\
\hline Villa deAranda & 55.00 & 10.00 & 22.22 & 49.44 & -1.12 & -2.22 & 49.94 & -0.12 & -0.23 & -45.8 \\
\hline BM Sinfin & 69.23 & 38.46 & 125.00 & 49.80 & -0.40 & -0.78 & 52.45 & 4.90 & 10.29 & 60.0 \\
\hline
\end{tabular}


Matos, R.; Amaro, N., \& Pollard, R. (2020). How best to quantify home advantage in team sports: an investigation involving male senior handball leagues in Portugal and Spain. RICYDE. Revista internacional de ciencias del deporte, 59(16), 12-23.

https://doi.org/10.5232/ricyde2020.05902

Comparing the rescaled method with the new method, when HA is very small, as in the case of goals scored and conceded, then values from the new method are about twice the magnitude of the rescaled method. However when HA is larger, as in the case of most of the teams in the lower half of the Spanish league table, when based on points, the new method produces HA values which are much higher that the rescaled.

\section{Discussion}

The main goal of the investigation was to assess and compare various methods of quantifying HA, with special emphasis given to a new approach. All methods produced a valid numeral measure, but with possible difficulties in interpretation of the magnitude of the values obtained. The new approach had the advantage of being applicable to differential measures of performance at home and away, such as the difference between goals scored and conceded. Before comparing the methods under consideration, a few general remarks about the interpretation of the results can be made. In Tables 3 and 4 it was observed that HA was greater when based on points than when based on goals. This phenomenon of HA being greater when based on the game result, as opposed to the scoring events (such as goals) contributing to the result, occurs in most sports. Basketball is the prime example. In the NBA in North America in season 2017-18, using the traditional method, HA was $57.9 \%$ when based on winning percentage (the game result), but only $50.5 \%$ when based on points, the scoring events that determine each game result (NBA 2017/2018 results, standings, n.d.). It should also be noted that when comparing HA from different leagues, competitive balance should be controlled for (Pollard \& Gómez, 2014), but this refinement was not needed for the current investigation, the focus of which is simply on the comparison of different methods of quantifying HA.

The trend seen in Tables 5 and 6 for the better teams to have lower HA when based on points is not unexpected since this has been demonstrated and discussed in previous studies, originally for basketball in Spain (Pollard \& Gómez, 2007) in which a method for controlling for team ability was introduced. This negative relationship between team ability and HA is because a strong team will tend to win its games both at home and away, thus masking much of the effect of HA when game result is the outcome measure. Thus for a comparison between teams, team ability would normally be controlled for, but again this was not the focus of the present investigation.

Turning to differences between the methods of quantifying HA, Stefani's method, though valid and mathematically sound, cannot be applied to individual teams, neither can it be applied to goals scored or goals conceded. For these reasons, it will not be considered further, especially since it can be shown to produce values for HA which are broadly similar to the rescaled method.

Since the three remaining methods are mathematically related, each one a transformation of the other, the main focus of comparison will be on their use and interpretation. The traditional method has the advantage of having been in general use for several decades. Although originally designed to quantify HA for football tables, it has been successfully applied to individual teams, to many different sports and to different competitions in different locations (e.g. Pollard, Prieto \& Gómez, 2017). One reason for this is its easily adaption to different points scoring systems, thus allowing for valid comparisons between competitions in which the result of a game is simply win/lose (e.g. basketball) or a more complicated awarding of points to the two teams depending, for example, on how draws (ties) are treated, as well as the awarding of a different number of points for different within-game outcomes (e.g. rugby, 
Matos, R.; Amaro, N., \& Pollard, R. (2020). How best to quantify home advantage in team sports: an investigation involving male senior handball leagues in Portugal and Spain. RICYDE. Revista internacional de ciencias del deporte, 59(16), 12-23.

https://doi.org/10.5232/ricyde2020.05902

American football). It can also be used to quantify the HA derived from other performance indicators, such as goals, shots, time of possession, fouls etc. As explained in the introduction, the interpretation of the word 'advantage' using this traditional method may be problematic, but can be solved by a simple rescaling the originally derived HA values.

The new method, for which consideration is proposed, adopts a somewhat different rationale. This relates home performance (points, goals etc.) directly against away performance, rather than against overall performance. This is achieved by looking at differences in percentage terms, quantifying changes from away performance to home performance. For instance, if a team gained 6 points away from home and 9 points at home, in a balanced competition, this would mean that, when playing at home, they improved their performance, compared with playing away to home, by $((9-6) / 6) * 100 \%$, giving a HA value of $50 \%$ using this method. This $50 \%$ figure means that, when playing at home, the team won $50 \%$ more points than when playing away. If the situation were the reverse ( 6 points won home and 9 away), figure would be $-33.3 \%$, resulting from $((6-9) / 9) * 100 \%$, representing a $33.3 \%$ home disadvantage (HD) or, focusing on HA, a -33\% home advantage. Points, goals scored and goals conceded are always positive figures and can all be treated in the same way.

However, when it comes to goal differential (goals scored - goals conceded), negative values will occur when a team concedes more goals than it scores, a situation that could occur either at home, or away from home, or both. The new method can be used in this situation, but to avoid misleading interpretations a slight modification to the formula needs to be made. The absolute value of away performance in the denominator needs to be used: HA (goal differential) $=((\mathrm{H}-\mathrm{A}) /|\mathrm{A}|) * 100 \%$, instead of $((\mathrm{H}-\mathrm{A}) / \mathrm{A}) * 100 \%$. Without this modification, a HA might become an apparent HD and vice-versa, leading to erroneous conclusions and interpretations. This would be the case for a team (or for all the teams when considering a complete league) that would lose, on average, their games by two goals away from home and win them by two goals at home. This double rollback, i.e., recovering the two goals disadvantage and raising the performance to a positive two goal figure, would produce a $200 \%$ HA $((2--2) /|-2|) * 100 \%$ $=4 / 2 * 100 \%=200 \%$. Without taking the absolute value of the away performance, the result would be $-200 \%$, wrongly suggesting a home disadvantage rather than a home advantage.

As stated before, with this method HA is not limited to a $100 \%$ maximum, since HA will depend upon the away performance. If the away goal differential value is very small, it will be quite easy to have a large HA. For example, if the home differential is 10 and the away differential is 1 , then HA will be $900 \%$. In contrast large away differentials will tend to produce smaller HA. This can be seen as, at the same time, advantageous (since it makes HA quite dependent upon the other side of the coin - performance away from home - stressing in a more natural way the real meaning of advantage) and disadvantageous, since it may prevent or, at least, hamper comparisons, since the HA scale will be unlimited, and dependent on the magnitude of the away measure under consideration.

Results showed that when HA is very small, as in the case of goals scored and conceded, then values from the new method are about twice the magnitude of the rescaled method. However when HA is larger, as in the case of most of the teams in the lower half of the Spanish league table, when based on points, the new method produces HA values which are much higher that the rescaled. 
Although all three methods of quantifying HA are perfectly valid, the choice will probably depend on what interpretation seems more meaningful in the situation under investigation.

One limitation of the new method proposed is that HA will be undefined if no points are won away, since the formula denominator value will be 0 . Furthermore, the main limitation of the study is the fact that its application has only been made on a single, relatively minor sport in one particular part of the world. Furthermore the two leagues appeared to have teams of widely differing abilities with the champion team in each league winning all its games both at home and away. A next step would be to assess the new method in a league in which there is more competitive balance. One of the main football leagues in Europe would be an obvious choice, with basketball and baseball in North America providing further possibilities being major league sports with differing levels of home advantage and different scoring systems (Gómez, Lago-Peñas \& Pollard, 2013).

\section{Conclusion}

It is well established that home advantage in team sport plays an important part of determining the result of a game. How to quantify the extent of this advantage is therefore an important consideration. The traditional and well establish method of doing this is easy to calculate and can be applied to different points scoring systems in different sports, as well as to other performance indicators such as goals scored. Criticisms of this method based on the interpretation of the word 'advantage' are valid, but if thought necessary these can easily be overcome by a simple rescaling of the values produced by the traditional method. A new method, elaborated for the first time, is shown to produce valid measures of HA, based on quantifying home performance specifically in relation to the corresponding performance away from home. This is in contrast with the traditional and rescaled methods which express home performance in terms of overall performance, home and away. The traditional and rescaled methods both ensure a maximum value of $100 \%$ for home advantage which has a sound logical basis, while the new method can produce values well above $100 \%$, giving rise to some difficulty in interpretation. However, this method provides a new dimension to consider, and a new tool to use, when trying to quantify home advantage. One advantage of the new method is that it can be applied to differential measures, such as the difference between goals scored and conceded. Choice of methodology will depend on the specific objective being sought in a study of the effect of home advantage on performance.

\section{References}

Clarke, S. R., \& Norman, J. M. (1995). Home ground advantage of individual clubs in English soccer. The Statistician, 44(4), 509-521. https://doi.org/10.2307/2348899

Courneya, K. S., \& Carron, A.V. (1992). The home advantage in sports competitions: A literature review. Journal of Sport and Exercise Psychology, 14(1), 13-27.

Debanne, T., \& Laffaye G, (2017). Effects of game location, quality of opposition, number of foreign players and anthrometric characteristics in elite handball games. Kinesiology, 49(2), 194-201.

Edwards, J. (1979). The homefield advantage. In J. H. Goldstein (Ed.), Sports, games, and play: Social and Psychological Viewpoints (pp. 409-430). Hillsdale, NJ: Lawrence Erlbaum. 
Gómez, M.A.; Lago-Peñas, C., \& Pollard, R. (2013). Situational variables. In T. McGarry, P. O'Donoghue and J. Sampaio (Eds.). Routledge Handbook of Sports Performance Analysis (pp 259-269). Abingdon, U.K.: Routledge.

Gómez, M. A.; Lago-Peñas, C.; Viaño, J., \& González-Garcia, I. (2014). Effects of game location, team quality, and final outcome on game related statistics in professional handball close games. Kinesiology, 46(2), 249-257.

Gómez, M.A., \& Pollard, R. (2014). Calculating the home advantage in soccer leagues. [Letter]. Journal of Human Kinetics, 40(1), 5-6. https://doi.org/10.2478/hukin-2014-0001

Gómez, M. A.; Pollard, R., \& Luis-Pascual, J-C. (2011). Comparison of home advantage in nine different professional team sports in Spain. Perceptual and Motor Skills, 113(1), 150-156. https://doi.org/10.2466/05.PMS.113.4.150-156

Goumas, C. (2017). Modelling home advantage for individual teams in UEFA Champions League football. Journal of Sport and Health Science, 6(3), 321-326. https://doi.org/10.1016/j.jshs.2015.12.008

Jamieson, J. P. (2010). The home field advantage in athletics: A meta-analysis. Journal of Applied Social Psychology, 40(7), 1819-1848. https://doi.org/10.1111/j.1559-1816.2010.00641.x

Jones, M. B. (2018). Differences in home advantage between sports. Psychology of Sport and Exercise, 34, 61-69. https://doi.org/10.1016/j.psychsport.2017.07.012

Lago-Peñas, C.; Gómez, M. A.; Viaño, J.; González-García, I., \& Fernández-Villarino, M. (2013). Home advantage in elite handball: the impact of the quality of opposition on team performance. International Journal of Performance Analysis in Sport, 13(3), 724733. https://doi.org/10.1080/24748668.2013.11868684

Meletakos. P., \& Bayios, I. (2010). General trends in European men's handball: A longitudinal study. International Journal of Performance Analysis in Sport, 10(3), 221228. https://doi.org/10.1080/24748668.2010.11868517

NBA 2017/2018 results, standings. (n.d.). Retrieved from: https://www.flashscore.com/basketball/usa/nba-2017-2018/standings/

Nevill, A. M., \& Holder, R. L. (1999). Home advantage in sport: An overview of studies on the advantage of playing at home. Sports Medicine, 28(4), 221-236. https://doi.org/10.2165/00007256-199928040-00001

Oliveira, T.; Gómez, M., \& Sampaio, J. (2012). Effects of game location, period, and quality of opposition in elite handball performances. Perceptual and Motor Skills, 114(3), 783794. https://doi.org/10.2466/30.06.PMS.114.3.783-794

Pic, M. (2018). Performance and home advantage in handball. Journal of Human Kinetics, $63,61-71$. https://doi.org/10.2478/hukin-2018-0007

Pollard, R. (1986). Home advantage in soccer: a retrospective analysis. Journal of Sports Sciences, 4(3), 237-248. https://doi.org/10.1080/02640418608732122 
Pollard, R., \& Gómez, M. A. (2007). Home advantage analysis in different basketball leagues according to team ability. Iberian Congress on Basketball Research, 4, 61-64.

Pollard, R., \& Gómez, M. A. (2012). Re-assessment of home advantage in Spanish handball. Comment on Gutiérrez, et al. (2012). Perceptual and Motor Skills, 115(3), 937-943.

https://doi.org/10.2466/06.05.PMS.115.6.937-943

Pollard, R., \& Gómez, M. A. (2014). Components of home advantage in 157 national soccer leagues worldwide. International Journal of Sport and Exercise Psychology, 12(3), 218233.

https://doi.org/10.1080/1612197X.2014.888245

Pollard, R., Prieto, J., \& Gómez, M. (2017). Global differences in home advantage by country, sport and sex. International Journal of Performance Analysis in Sport, 17(4), 586-599. https://doi.org/10.1080/24748668.2017.1372164

Saavedra, M.; Gutiérrez, O.; Sa Marquez, P.; Torres, G., \& Fernández, J. J., (2013), Calculating home advantage in the first decade of the $21^{\text {st }}$ century UEFA soccer leagues. Journal of Human Kinetics, 38, 141-150. https://doi.org/10.2478/hukin-2013-0054

Schwartz, B., \& Barsky, S. F. (1977). The home advantage. Social Forces, 55(3), 641661. https://doi.org/10.1093/sf/55.3.641

Smith, D. R. (2003). The home advantage revisited. Winning and crowd support in an era of national publics. Journal of Sport and Social Issues, 27(4), 346-371. https://doi.org/10.1177/0193732503258637

Stefani, R. (2007). Measurement and interpretation of home advantage. In J. Albert and R.H. Koning (Eds.), Statistical thinking in sports (pp. 203-216). London: CRC Press. 